\title{
Evaluation of dental enamel color after fixed orthodontic therapy using two types of protectors to prevent white spot lesions (A prospective clinical study)
}

\author{
Yasir Ruda Allabban ${ }^{(1)}$ \\ Article DOI: $\underline{\text { https://doi.org/10.26477/jbcd.v32i2.2889 }}$
}

\begin{abstract}
Background: The aim of this study is to evaluate the color change $\Delta \mathrm{E}$ of the dental enamel following treatment with 2 kinds of protector (icon infiltrant, clinpro varnish) before fixed orthodontic treatment to avoid the possible white spot lesions.

Materials and Methods: Fifty four subjects treated with fixed appliances were divided into 3 groups: the 1st group was control, while the $2^{\text {nd }}$ and $3^{\text {rd }}$ groups were treated with icon infiltrant and clinpro varnish before bonding procedure, respectively. Color parameters $(\mathrm{L}, \mathrm{a}, \mathrm{b})$ were recorded for the middle and gingival thirds before and after bonding procedure to get the $\Delta \mathrm{E}$ of each group.

Results: One-way ANOVA test showed a non-significant difference in $\Delta \mathrm{E}$ between the 3 groups at $\mathrm{p}$ value $<0.05$, while there were highly significant differences in value of $\Delta \mathrm{E}$ between middle thirds and the gingival thirds in all groups.

Conclusion: The icon infiltrant and clinpro varnish have no effect on color of the enamel when used before the bonding procedure. Color change $\Delta \mathrm{E}$ occurring in middle third is higher than that of the gingival third.
\end{abstract}

Keywords: Color change, protector, white spot lesions. (Received:28/5/2019; Accepted:30/6/2019)

\section{Introduction}

White spot lesions (WSLs) are white milky patches that develop around the brackets in fixed orthodontic treatment due to demineralization of dental enamel as this demineralization is due to plaque attack. ${ }^{(1)}$ The WSL is a disappointing problem arising during and after fixed orthodontic treatment. ${ }^{(2)}$ The aggressiveness of dental plaque increases due to change in oral microbiota and difficulty to maintain oral hygiene in the presence of fixed orthodontic appliance. ${ }^{(3)}$ According to Souza et al. ${ }^{(4)}$ WSL occurs in approximately $50 \%$ of fixed orthodontic patients, this important problem motivates both the manufacturer and the researcher to do enough investigation for prevention and / or treatment of WSL..$^{(5-9)}$ That is why several products are available in the market for prevention and/or treatment of WSL. This study will focus on the icon infiltrant resin (DMG) and glass ionomer cement (clinpro XT varnish, 3M Unitek) because it has been shown that the use of these products before bracket bonding would not interfere with or reduce the shear bond strength. ${ }^{(10)}$ So it is wise to use one of these products before bonding particularly for risky patients who have incipient caries, history of WSL, non-cavity lesion and the unbalanced mouth with repeated acid attacks, so the demineralization process is faster than remineralization. ${ }^{(11)}$

(1) Assist. Prof. in Department of Orthodontics, College of Dentistry, University of Baghdad.

Corresponding author, yassir.patent@gmail.com
Patients nowadays are not satisfied by correction of malocclusion only, but the color of the teeth plays an important role in the esthetic outcome. ${ }^{(12-}$ 14) Insufficient information about the enamel color behavior is available so far. This study aims to investigate the effect of the above mentioned two protectant materials on enamel color when used under the bracket. The first research hypothesis is that the dental enamel may become darker in color as a result of using those agents. The second hypothesis is that the dental enamel may behave in a different manner (regarding the color) due to materials difference.

The third hypothesis is that enamel behavior after application of these materials will differ according to the regain and anatomy of the labial aspect.

\section{MATERIALS AND METHODS}

The sample comprised of 54 individuals, 27 males and 27 females within an age range between 1840 years; all were candidates for fixed orthodontic therapy. All the details about this research were explained to them so they agreed and singed the consent form. The inclusion criteria:

1- Full permanent dentition and crowding less than $4 \mathrm{~mm}$.

2- No caries, restoration, prosthesis or decalcification in the teeth.

3- No gingival inflammation.

4- No smoking ${ }^{(15)}$.

All the patients received scaling and polishing prophylaxis, and were motivated to follow oral hygiene protocol including regular teeth brushing with fluoridated tooth paste and never use any mouth wash like chlorhexidine to avoid teeth 
staining. All patients were prepared for bonding but before the bonding procedure took place all patients underwent color measurement recording for the gingival and middle thirds of the upper six anterior teeth by using spectrophotometer vita easy shade compact (vita zahn fabric, bad sackingen, Germany). ${ }^{(15-16)}$ The color of the teeth was explained by 3 parameters: (L, a, b) according to commission of international of del eclairage, ${ }^{(17)}$ where the $\mathrm{L}$ parameter represents the value or degree of lightness in munsell system ranging from $\mathrm{O}$ (black) to 100 (white), while the "a" parameter represents a measure of redness $(a>0)$ or greenness $((a<0)$ and $b$ represent parameter of yellowness $(b>0)$ or blueness $(b<0){ }^{(18)}$ To avoid any error in color measurement, the method was standardized to overcome any confounder variable, in which all measurements were done in the same environmental light. The easy shade device was used according to manufacturer instructions by the same operator who passed the calibration for using this device one week before starting this research. ${ }^{(3)}$ The operator recorded the ( $\mathrm{L}, \mathrm{a}$, and $\mathrm{b}$ ) variables for the middle and gingival thirds of each upper anterior tooth. The easy shade device was used by holding the sterile intra oral device tip (mouth piece) perpendicular to the labial surface of the tooth just touching the gingival margin (for gingival third), in the same manner the record for the middle third was by sliding the device tip to the center of the clinical crown. ${ }^{(15)}$

After finishing color measurement registration for all patients included in this study, the sample was divided randomly into 3 groups (each group consisted of 9 males and 9 females): group one is a control group that received bonding in a conventional way without using any material before the bonding procedure, in the $2^{\text {nd }}$ group we used icon (DMG, lambug, Germany), a low viscosity infiltrant resin, before the bonding procedure, while in the $3^{\text {rd }}$ group we used the clinpro XT varnish (3M Unitek, Landsber, Germany), a glass ionomer cement, before the bonding procedure. Both protective materials used in groups 2 and 3 were used according to manufacturer protocol as shown in table (1). ${ }^{(10)}$

Table 1: Groups, material and application protocol used in the current study.

\begin{tabular}{|c|c|c|c|c|c|}
\hline Grou & pNumber & Material & Manufacturer & Composition & Application \\
\hline 1 & 18 & None & & & \\
\hline 2 & 18 & $\begin{array}{l}\text { Icon } \\
\text { infiltrant }\end{array}$ & $\begin{array}{l}\text { DMG } \\
\text { (Hamburg } \\
\text { Germany) }\end{array}$ & $\begin{array}{c}\text { 1-Icon -etch hydrochloric acid } \\
\text { salicylic pyrogenic acid } \\
\text { 2-Icon Dry } 99 \% \text { Ethanol } \\
\text { 3-Icon infiltrant resin matrix based } \\
\text { on methacrylates, primer and } \\
\text { additives. }\end{array}$ & $\begin{array}{l}\text { 1- the etch applied for } 120 \mathrm{sec} \text {. } \\
\text { 2- applied for } 30 \mathrm{sec} \text { with air } \\
\text { drying. } \\
\text { 3-applied for } 180 \mathrm{sec} \text { reapplied for } \\
60 \mathrm{sec} \text { then cured for } 40 \mathrm{sec} \text {. }\end{array}$ \\
\hline 3 & 18 & $\begin{array}{c}\text { Clinpro } \\
\text { XT varnish }\end{array}$ & $\begin{array}{c}\text { 3M } \\
\text { Unitk } \\
\text { (Landsberg } \\
\text { Germany) }\end{array}$ & $\begin{array}{c}\text { Silanized glass powder, silica } \\
\text { treated with silicon methacrylate, } \\
\text { 2-hydroxy ethil water, BIS - } \\
\text { GMA. } \\
\text { Copolymer of acrylic acid and } \\
\text { itaconic. }\end{array}$ & $\begin{array}{l}35 \% \text { phosphoric acid for } 20 \mathrm{sec} \\
\text { then washing and air drying, } \\
\text { mixing the components } \\
\text { application and cured for } 20 \mathrm{sec} .\end{array}$ \\
\hline
\end{tabular}

In sequence after the application of icon to group 2 and clinpro to group 3 while leaving group 1 (control group) untreated with any material before bonding procedure took place.

All the groups were subjected to polishing of teeth with rubber cup and non-fluoridated pumice, sprayed with water and then dried with oil-free compressed air stream, and then teeth were etched (35\% phosphoric acid gel, $30 \mathrm{sec}$ washed with water and dried by air blowing). (10) Bonding procedure was done for all groups by the same type of adhesive and bracket. Finally at the end of orthodontic treatment deboning procedure was done using bracket removing pliers, while the remaining adhesive was removed with help of 12 fluted tungsten carbide bur (Komet Gebr, Brasseler, Lamgo, Germany) with low speed under water cooling. Then finishing was conducted with extra fine sof-lex polishing discs (3M FSPE Dental product, 3Mcenter) until achieving the luster of the enamel. New burs and discs were used for every subject in this study. ${ }^{(15)}$ All the processes of adhesive removal and finishing were achieved with naked eye to simulate the clinical environment ${ }^{(19)}$. Then another color measurement for the upper six interior teeth in the same method, operator and device under the same circumstances were recorded as post-operative measurements. The color difference $\Delta \mathrm{E}$ between the first color measurement before bonding of the all groups and the second color measurement after debonding was calculated by the following equation:

$\Delta \mathrm{E}=\left[\left(\mathrm{L}_{1}-\mathrm{L}_{2}\right)^{2}+\left(\mathrm{a}_{1}-\mathrm{a}_{2}\right)^{2}+\left(\mathrm{b}_{1}-\mathrm{b}_{2}\right)^{2}\right]^{1 / 2}$ 
Where $\Delta E$ represents color difference or change, while $\mathrm{L} 1$ represents the mean of the $\mathrm{L}$ value for each specific third, for example counting L1 for gingival thirds of upper anterior teeth according to following equation. ${ }^{(20)}$

\section{L1 of gingival third of the upper teeth}

\begin{tabular}{|c|c|c|c|c|}
\hline \multicolumn{5}{|c|}{ No of upper anterior teeth } \\
\hline dure we can count $\mathrm{a} 1$ and $\mathrm{b} 1$ for & First group & 18 & 3.97 & 0.95 \\
\hline according to the upper equation, & Second group & 18 & 3.83 & 0.77 \\
\hline th gingival thirds of upper teeth & Third group & 18 & 4.44 & 0.84 \\
\hline
\end{tabular}

F test $=2.67 ; P$ value $=0.087$, d.f. $=53(\mathrm{NS})$ as one segment by calculating the average of the $\mathrm{L}$, a and b; the same thing will apply for the middle thirds so each third either gingival for middle will have one average of the L1, a1 and b1. ${ }^{(3,20)}$

Descriptive statistics included means and standard deviation for both male and female subgroups in the three major groups, also independent sample ttest was used to find any gender difference within each group. One-way ANOVA test was applied to compare $\Delta \mathrm{E}$ in 3 groups included in this study for the gingival thirds and the middle thirds. Again independent sample t-test to compare the $\Delta \mathrm{E}$ between gingival thirds and middle thirds in each group.

\section{RESULTS}

Table 2 shows means, standard deviation of the $\Delta \mathrm{E}$ for the each gender subgroup in the main three groups included in this study. The t-test showed no significant difference between the male and female subgroups at a level of significance $\mathrm{p}<$ 0.05 , so it is wise to pool the data of both gender subgroups in all three main groups in the present study. Also, table 2 shows the mean of the $\Delta \mathrm{E}$ in the middle thirds is higher than that of the gingival thirds, the difference was highly significant, $\mathrm{p}$ $<0.001$ as in table 5. Table 3 and 4 show the difference in color change $\Delta \mathrm{E}$ between the main three groups either for the gingival or the middle thirds, ANOVA showed no significant difference between these three groups.

Table 2: descriptive statistics and gender difference for the $\Delta \mathbf{E}$ within each group.

\begin{tabular}{|l|l|c|c|c|c|c|}
\hline \multirow{3}{*}{ Group } & \multirow{2}{*}{ Region } & \multicolumn{2}{|c|}{$\begin{array}{c}\text { Males } \\
\text { N=9 }\end{array}$} & \multicolumn{2}{c|}{$\begin{array}{c}\text { Females } \\
\text { N=9 }\end{array}$} & $\begin{array}{c}\text { T test } \\
\text { d.f.=16 }\end{array}$ \\
\cline { 3 - 8 } & & Mean & S.D & Mean & S.D & P value \\
\hline \multirow{2}{*}{ First } & Gingival & 3.93 & 0.91 & 4.01 & 1 & $0.164(\mathrm{NS})$ \\
\cline { 2 - 7 } & Middle & 4.35 & 0.88 & 4.42 & 0.85 & $0.79(\mathrm{NS})$ \\
\hline \multirow{2}{*}{ Second } & Gingival & 3.89 & 0.6 & 3.77 & 0.94 & $0.69(\mathrm{NS})$ \\
\cline { 2 - 7 } & Middle & 4.22 & 0.79 & 4.11 & 0.66 & $0.74(\mathrm{NS})$ \\
\hline \multirow{2}{*}{ Third } & Gingival & 4.51 & 0.91 & 4.37 & 0.77 & $0.81(\mathrm{NS})$ \\
\cline { 2 - 7 } & Middle & 5.1 & 0.49 & 4.99 & 0.95 & $0.84(\mathrm{NS})$ \\
\hline
\end{tabular}

Table 3: ANOVA test to detect the difference in $\Delta \mathbf{E}$ between the three groups included in this study for the gingival thirds.

\begin{tabular}{|l|l|l|l|} 
Groups & Number & Mean & SD \\
\hline
\end{tabular}

Table 4: ANOVA test to detect the difference in $\Delta E$ between the 3 groups included in this study for the middle third.

\begin{tabular}{|l|c|l|l|}
\hline Groups & Number & Mean & SD \\
\hline First group & 18 & 4.38 & 0.86 \\
\hline Second group & 18 & 4.16 & 0.72 \\
\hline Third group & 18 & 5.04 & 0.72 \\
\hline
\end{tabular}

$F$ test $=4.052 ; P$ value $=0.27$, d.f. $=53(\mathrm{NS})$

Table 5: Independent sample t-test to compare the value of $\Delta \mathbf{E}$ difference between middle and gingival third for the three groups included in this study.

\begin{tabular}{|l|c|l|l|}
\hline Groups & Number & t-test & p-value \\
\hline First group & 18 & 4.996 & 0.001 \\
\hline Second group & 18 & 3.331 & 0.001 \\
\hline Third group & 18 & 5.023 & 0.001 \\
\hline
\end{tabular}

\section{DISCUSSION}

In the present study we tried to explore the enamel color changes due to the use of recent prophylactic protector agents like the icon infiltrant and the clinpro Xt varnish, to get rid of the possible clinical problem white spot lesion (WSL) that develops shortly after the fixed braces treatment. To be more specific, the labial aspects of the upper anterior teeth have been divided into 3 thirds: gingival, middle and incisal (the incisal thirds were omitted in this study because these protectors are indicated to be used only in peribracket area and the WSLs are unlikely to develop in the incisal region since it is regarded as self- cleanable area. ${ }^{(1,2,21,22)}$ The majority of the previous studies included the effect of the above materials on enamel color were in vitro studies, but we do not know how far these materials will affect the enamel color in clinical trials.

Table 2 shows a strong similarity between the $\Delta \mathrm{E}$ of the control group and the $2^{\text {nd }}$ icon infiltrant group, whereas table 3 and 4 show no significant difference between them. This result disagreed with Matteo et al. ${ }^{(22)}$ who exposed the extracted and icon infiltrant treated teeth to red wine and coffee, also our results disagreed with Andero et al. (23) who induced the WSLs for the extracted teeth and then treated them with icon infiltrant then exposed the treated teeth to red wine and 
coffee; the above two disagreements are due to difference in methodology since these previous studies are vitro while the present study is a vivo study. Also in the present study we did polishing with pumice before the bonding procedure took place, this polishing may remove the infiltrant layer. On the other hand the result of this study (concerning the icon infiltrant) agreed with Soyeon bak et al. ${ }^{(24)}$ who did WSLs to the extracted teeth, then treated them with icon infiltrant resulting in restoring healthy enamel color. Regarding the $3^{\text {rd }}$ group clinpro varnish, the $\Delta \mathrm{E}$ in this group is higher than the control and $2^{\text {nd }}$ icon infiltrant group (table 2) although the difference is not significant either in gingival or middle thirds (table 3, 4).

This result agreed with Nicoleta et al. ${ }^{(25)}$ who did assessment for the surface discoloration of the enamel after application of the clinpro and after exposure to artificial aging and staining solutions, they found no significant difference in color stability. Again Nicoleta et al. (26) did another study to evaluate the effect of clinpro on bleaching power for natural teeth, so they took natural teeth as substrate, half of them were sealed with clinpro varnish and the other act as control, then they used office bleaching for both groups and did color measurement before and after the bleaching procedure they found that there was no significant difference between the 2 groups, according to the above both of the icon infiltrant and clinpro varnish had no significant difference on the enamel's color if they were used prior to bonding of the fixed braces, in spite of the clinpro varnish group showing higher $\Delta \mathrm{E}$ than both the control and icon infiltrant, but the difference is not significant, and the dental enamel behaves in similar ways with both protector materials. So according to the results of the present study, the $1^{\text {st }}$ and $2^{\text {nd }}$ hypotheses were rejected since both materials showed no effect on enamel color and the latter behaved the same with both of them in spite of their differences.

Regarding the regional differences in $\Delta \mathrm{E}$, the value of the $\Delta \mathrm{E}$ in middle third of all three groups is significantly greater than that of the gingival thirds, this result agreed with Allabban ${ }^{(20)}$, the darker color of the middle thirds may be due to the presence of the bracket in the middle third so the bracket acts as a protector for the middle third from the abrasion of teeth brushing, on the other hand the gingival thirds are subject to the abrasion of teeth cleaning and this abrasion is enough to remove the infiltrated enamel layer with protecting and/or bonding agent and exposing new fresh enamel layer, because the infiltrated enamel with any materials, all the time looks darker than virgin enamel surface due to infiltrated resin tags that absorb water and stains from the oral environment.

\section{CONCLUSION}

1- Both the icon infiltrant and clinpro varnish have no adverse effects on enamel color when used before the bonding of fixed braces as protecting agents against WSLs.

2- The gingival thirds show less color change after fixed orthodontic treatment whether we use protector agents or not.

\section{Conflict of interest: None.}

\section{REFERENCES}

1. Al-jaibehji M. The influence of caries infitrant combined with and without conventional adhesives on sealing of the sound enamel (in vitro study). A thesis submitted to the College of Dentistry, University of Baghdad, 2014; 14-15.

2. Moreira TC, Sampaio RKL. Efeitor do tratamento ortodontico sobre o esmalto desmineralizacaoi e pigmentacao. rev dental prss ortod ortop facial 2001 mar-apr; 6(2): 41-8

3. Freit AO, Marquezan M, Nojma MC, Alviano DS, Maia LC. The influence of orthodontic fixed appliance on the oral microbiota: a systematic review. Dental Press J Orthod. 2014;19(2):46-55.

4. Souza de-Silva CM, Parisotto TM, Steiner-Oliveira C, Kamiya RU, Rodrigues LK, Nobre-doso- Santos M. Carbon dioxide laser and bonding material reduce enamel demineralization around orthodontic bracket. Lasers Med Sci. 2013;28(1):111-8.

5. Benson PE, Shah AA, Millett DT, Dyer F, Parken N, Vine RS. Fluorides, orthodontics and demineralization: A systematic review. J Orthod. 2005;32(2):102-14.

6. Benson JG, van der Veen MH, Lagerweij MD, Bokhout B, Prahl-Andersen B. Canes prevalence measured with QLF after treatment with fixed orthodontic appliances; influence factor. Caries Res. 2005;39(1):41-7.

7. Ahn SJ, Lim BS, Lee YK, Nahm DS. Quantitative determination of adhesion patterns of cariogenic streptococci to various orthodontic adhesives. Angle Orthod. 2006; 76(5):869-75.

8. Kerbusch AE, Kuijoers-jagtman AM, Mulder J, Van der sanden WJ. Prevention of white spots during orthodontic treatment with fixed appliance. Ned Tijdschr Tandheelkd. 2010;117(5):283-7.

9. Shungin Dolsson AL, Persson M. Orthodontic treatment -related white spot lesions. A 14 year prospective quantitative follow-up including bonding material assessment Am J Orthod Dentofacial Orthop. 2010;138(2):136-7.

10. Vianna Julia Sotero, Marquezan Mariana, lau Thiago chon leon, Sant Anna Eduardo Franzotti. Bonding brackets on white spot lesions pretreated by means of two methods. Dental Press J Orthod. 2016; 21(2):3944.

11. Chang HS, Walsh LJ, Freer TJ. Enamel demineralization during orthodontic treatment. 
Aetiology and prevention, Aust Dental J. 1997; 42:(5):322-7.

12. Isiksal E, Hazar S, Akyalcin S. Smile esthetics: perception and comparison of treated and untreated smile. Am J Orthod Dentofacial Orthop. 2006;129: 816.

13. Al-Maaitah EF, Abo Omar AA, Al-Kateeb SN. Effect of fixed orthodontic appliance bonded with different etching techniques on tooth color: A prospective clinical study. Am J Orthod Dentofacial Orthop. 2013; 144: 43-9.

14. Hibemon LF, Maia LEG, Marcus VA. Influence of the esthetic bracket (color, translucence, and fluorescence) on visual perception. Am J Orthod Dentofacial Orthop. 2012;141:460-7.

15. Allabban YR. Comparison of enamel color alteration between bonded and free unbonded surface of Maxillary anterior teeth after fixed orthodontic therapy (a prospective clinical study). J Baghdad Coll Dent. 2015;27(3):174-78.

16. Judeh A, Al-wahadni A. A comparison between conventional visual and spectrophotometric for shade selection. Quitessence Int. 2009;40:e69-79.

17. Brewer JD, Wee A, Seghi R. Advance in color matching. Dent Clin North AM. 2004; 48:341-58.

18. Rakyali G, Ozdemir FI, Arun T. Enamel color changes at debonding and after finishing procedure using five different adhesives. Eur J Orthod. 2009; 31: 397- 401 .
19. Zaher AR, Abdalla EM, Abdel Moti MA, Rehman. Changes after debonding using various bonding systems. J Orthod. 2012;39:82-8.

20. Allabban YR. Response of dental enamel to office external bleaching following fixed orthodontic treatment using two types of orthodontic adhesives (clinical prospective study). IJSR. 2017; 6(4): 16381642.

21. Rengin A, Bongna S, Defne K, Michael K, Drik W, Thomas A. Shear bond strength of brackets to demineralize enamel after different pretreatment methods. Angle Orthod. 2012;82(1):56-61.

22. Matteo C, Davide R, Matteo V, Ricardo B, Marco C, Marco Co, Claudio P. Resin infiltrant for noncavitated caries lesions: evaluation of color stability. J Clin Exp Dent. 2017;9(2):e231-7.

23. Andrew L, Sercan A, Jeryl D, Eser T, Rade P. Evaluation of staining and color changes of a resin infiltration system. Angle Orthod. 2016;86 (6):900-4.

24. So-Yeon B, Young-Jae K, Hong-Keun Hyun. Color change of white spot lesions after resin infiltration. Color Res App. 2014; 39(5):506-10.

25. Nicoleta C, Alexander J. Hassel. Effect of staining and polishing on different types of enamel surface sealant. J Esth Rest Dent. 2018; 30(4).

26. Nicoleta C, Hassel AJ, Sinan S, Zingler S. Effect of enamel sealant on tooth bleaching and on the color stability of the result. Odontology. 2016;105(2):31-9.

الهدف من هذه الدر اسة هو تقييم التغير اللوني لميناء السن بعد معاملته بنوعين من مواد الحماية وهي ايكون المتغلغل و كلنبرو فارنيش

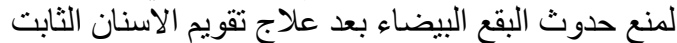

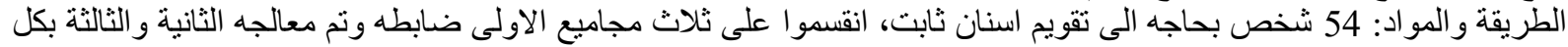
من ايكون المتغلل وكلنبرو فارنيش على الترنيب قبل نتبيث الحو اصر التقويثية ،

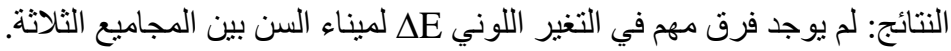

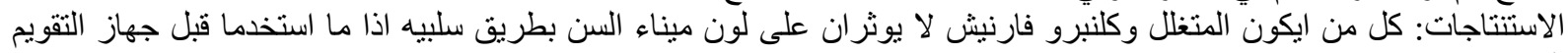
الثابت. 